\title{
Conceptual Design Evaluation of Concurrent Brake Actuator Mechanism
}

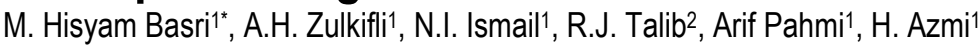

${ }^{1}$ School of Mechanical Engineering, College of Engineering, Universiti Teknologi MARA Cawangan Pulau Pinang,

Kampus Permatang Pauh, 13500 Permatang Pauh, Pulau Pinang, Malaysia

2Zeta Scientific Sdn. Bhd, Blok 5, Kompleks Otomobil, 23-1B, Jalan Pahat H15/H, Seksyen 15,

40200 Shah Alam, Selangor, Malaysia

*corresponding author: mhisyam.mbasri@uitm.edu.my

\section{ABSTRACT}

Since the number of motorcycles involved in accident has increased every year, the performance of motorcycle braking system should be optimized. Thus, the proper amount of braking force on both wheels is needed to optimize the braking performance and stability of the motorcycle. The braking effectiveness can be maximized by keeping the ideal nonlinear brake force distribution during braking. Therefore, the purpose of this research is to present a mechanism that can be accommodated as a Concurrent Brake Actuator (CBA) design to control the ideal nonlinear brake force distribution. In this paper, the conceptual design of the CBA mechanism was developed to be used as a based mechanism design for further CBA development. Two mechanism design concepts were generated using tilted position linear slope and nonlinear radius profile of the cam roller. The proposed concept designs were evaluated based on Design Failure Mode and Effect Analysis (DFMEA) and SOLIDWORKS Motion Analysis. The potential failure of the CBA concept design was determined based on the risk priority number (RPN) in DFMEA. The information obtained from DFMEA was used in SOLIDWORKS Motion Analysis to identify stress performance analysis for each CBA conceptual design. Then, the best CBA concept design was selected. The selection was made based on the highest score gained by the CBA concept design in qualitative evaluation. Based on the results, the fixed main body design with a tilted position linear slope in CBA Design I has the potential to actuate and distribute the nonlinear brake force to the front and rear brake with less potential of failure. Therefore, the proposed mechanism design will be used as a base mechanism design for further CBA development.

Keywords: conceptual design, concurrent brake actuator, brake actuator mechanism

\section{Nomenclature}
$M_{A}$
moment arm A
$M_{B} \quad$ moment arm B

$\begin{array}{ll}\text { Abbreviations } & \\ \text { BC } & \text { Boundary Condition } \\ \text { CAD } & \text { Computer-Aided Design } \\ \text { CBA } & \text { Concurrent Brake Actuator } \\ \text { DFMEA } & \text { Design Failure Mode and Effect Analysis } \\ \text { RPN } & \text { Risk Priority Number } \\ \text { WHO } & \text { World Health Organization }\end{array}$

\subsection{INTRODUCTION}

Motorcycle accidents have become a persistent problem in developing countries and developed countries. The number of fatalities in this accident is much higher compared to other vehicle accidents. World Health Organization (WHO) reported that the number of road traffic fatalities continues to rise steadily. In 2016, the total number of road traffic fatalities reached 1.35 million. Out of this figure, $28 \%$ of the total fatality comprised of motorcycle riders [1]. The majority of fatality recorded among motorcycle riders was $43 \%$ and $36 \%$ from all fatalities in South-East Asia and the Western Pacific, respectively. It shows that the motorcycle riders' fatalities constitute a significant concern in South-East Asia since it is one of the highest compared to other regions in the world [2-3]. Within South-East Asia, the percentage of motorcycle rider fatalities for Thailand and Laos is the highest with 74\% of fatality [3]. Then, it is followed by Cambodia, Malaysia, and Vietnam with 70\%, 59\%, and 
$58 \%$ of motorcycle riders who died of road accidents, respectively [4-5]. Meanwhile, in Colombia, the percentage of motorcycle rider fatalities increased to $42 \%$ in 2012 compared to $39 \%$ in 2010 [6]. In France, motorcycle riders accounted for $21 \%$ of traffic fatalities [7]. In comparison, the figure is $19 \%$ in the United Kingdom (UK) and $17 \%$ in the European Union (EU) [8-9]. Besides that, the number of motorcycle riders' fatalities also increases in the United States every year which reached 5,091 fatalities in 2008 [10].

The figure is quite alarming because accident always involves injury and fatality. Motorcycle riders are vulnerable to injuries due to less physical protection during accidents compared to car drivers and other vehicles. Therefore, vehicle safety system has been proposed to minimize the occurrence and consequence of motorcycle accidents. The improvement of this safety system has steadily reduced injury and death rates among motorcycle riders. These safety systems can be categorized into two major groups, which are passive safety systems and active safety systems. The purpose of passive safety systems is to protect the riders during an accident as well as to reduce the consequence of accident. In contrast, the active safety system helps to prevent motorcycles from an accident and thus contributes to the reduction of accident cases [11-12]. For the active safety systems, the brake system is the primary system in this category [12].

Recent studies showed that high braking performance can be achieved with the variation of braking force distribution [13]. The braking effectiveness can be maximized by keeping the ideal nonlinear brake force distribution during braking. The ideal nonlinear brake force distribution can be defined as the condition where a simultaneous wheel lock is obtained on both wheels during braking [14-15]. This condition can be achieved using Concurrent Brake Actuator (CBA). The CBA is used to control the required nonlinear brake force distribution to the front and rear brake of the motorcycle. In order to exhibit the ideal nonlinear braking force distribution of the motorcycle, the ratio of the moment arm has to be increased with the increasing of actuation force intensity. A passive compliant actuator shows excellent potential on this control task due to its ability to control the moment of force during the actuation.

As such, the purpose of this research is to present a mechanism that can be accommodated as a CBA design to control the ideal nonlinear brake force distribution. In this paper, the conceptual design of the CBA mechanism was developed to be used as a based design for CBA development. Two conceptual designs of the CBA mechanism were generated. All the proposed concept designs were evaluated based on Design Failure Mode and Effect Analysis (DFMEA) and SOLIDWORKS Motion Analysis. The potential failure of the CBA concept design was determined based on the risk priority number (RPN) in DFMEA. The information obtained from DFMEA was used in SOLIDWORKS Motion Analysis to identify stress performance analysis for each CBA conceptual design. The best design selection was made based on the highest score gained by the CBA concept design in qualitative evaluation.

\subsection{METHODOLOGY}

\subsection{Conceptual design of the CBA mechanism}

This section describes the development process of the conceptual design that proposes the mechanism for CBA. The CBA device shall be able to control the force distribution on the rear and front-wheel brakes to enhance the braking performance of the motorcycle. The nonlinear force distribution can be achieved by using the concept of the moment [16-18], as illustrated in Figure 1. The changes in the ratio between moment arm A, $M_{A}$, and moment arm B, $M_{B}$ produced a different output force to the front and rear brake. Hence, the ratio of the moment arm needs to be controlled according to the actuation force from the hand lever or foot pedal. In order to exhibit the ideal braking behaviour of the motorcycle, the ratio of the moment arm has to be increased with the increase of actuation force intensity. A passive compliant actuator showed excellent potential on this control task due to its ability to control the moment of force during the actuation.

Actuation by Hand Lever / Foot Pedal

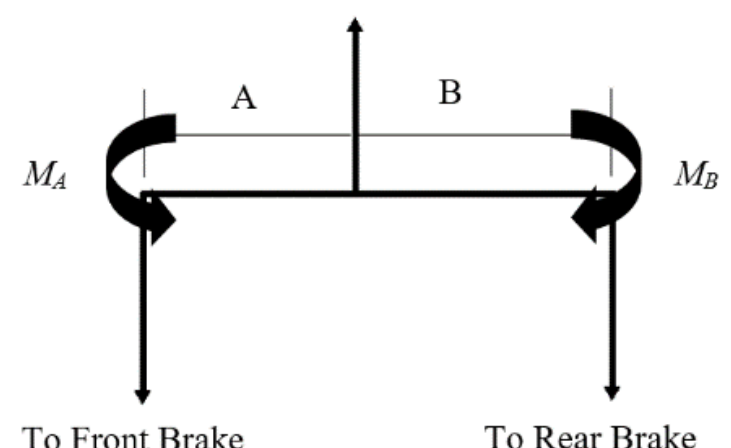

Figure 1. Basic Idea of CBA 
Based on the basic idea of CBA and the concept of passive compliant actuator, two CBA mechanism concept designs were proposed, as shown in Figure 2. The proposed designs were modeled into 3-dimensional computeraided design (CAD) models. It was modeled at the actual scale with the overall dimension of $120 \mathrm{~mm}(\mathrm{H}) \mathrm{x} 170$ $\mathrm{mm}(\mathrm{W})$. This mechanism changed the arm distance during the actuation by hand lever or foot pedal. Thus, it produced a different output force to the front and rear brake. The fixed main body was proposed for the first CBA concept design. This CBA concept design is known as CBA Design I. The fixed main body was designed with a tilted position linear slope. Two balls bearing rollers were used to control the movement along the main body. Despite controlling the movement, the ball bearing roller was used to produce the frictionless movement of the mechanism. The position of one roller was fixed, and another roller was moved along the elongated hole. The roller movement along the elongated hole was relative to the arm movement. This movement stretched the spring and forced the roller to move along the main body. The actuation force moved the arm from a hand lever or foot pedal. Then it distributed the force to the front and rear brake. The front brake actuated through the shaft center of the roller in the elongated hole. Meanwhile, the rear brake actuated through the fixed point on the arm. The horizontal distance of arms A was increased by moving the roller in the elongated hole relative to the arm movement. However, the horizontal distance of arms B was kept constant during the actuation. Hence, the nonlinear force distribution was obtained on the front and rear brake.

Despite the CBA design using the fixed main body, the second CBA conceptual design using the nonlinear radius profile of the cam roller design named as CBA Design II was proposed. The cam roller rotation was relative to the main body movement. The movement of the main body was controlled by the actuation force from the hand lever or foot pedal. Meanwhile, the actuation force on the front and rear brake was applied through the center shaft of the ball bearing roller and cam roller. The cam rotation shall control the horizontal distance between the cam roller and the ball-bearing roller. Spring was connected between the cam roller and the ball bearing roller to control the contact force of both rollers to the main body. The horizontal distance of arms A increased with the rotation of the cam roller relative to the main body movement, while the horizontal distance of arms B was fixed. This action produced the nonlinear force distribution on the front and rear brakes. The cam roller was attached to the ball bearing to produce frictionless movement. The CBA design used a cam roller with a nonlinear radius profile that has the potential to produce nonlinear force distribution to the front and rear brake.

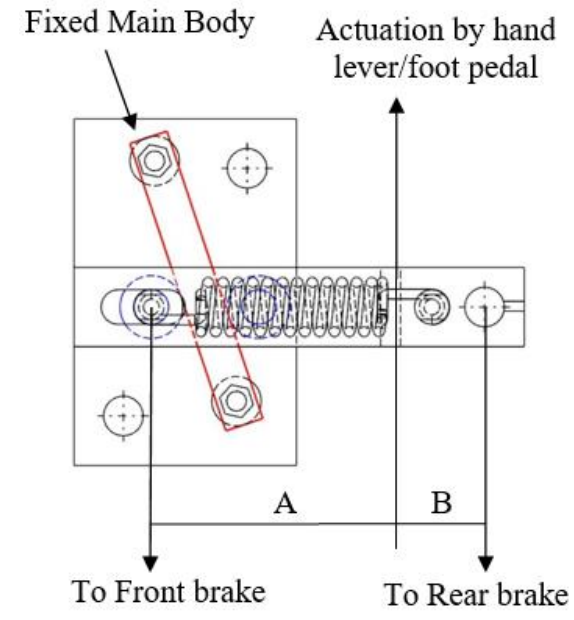

(a)

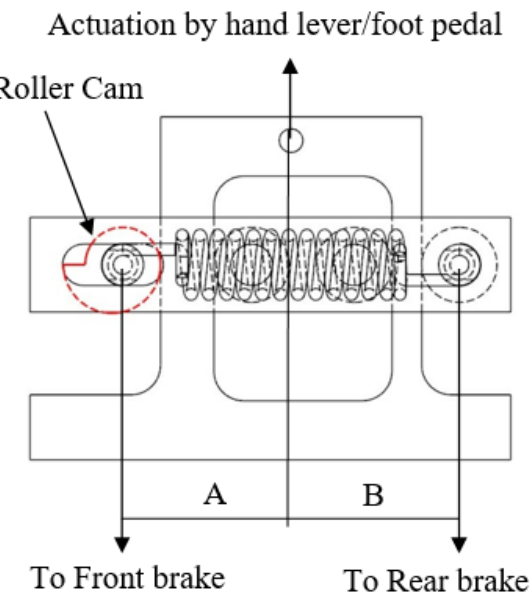

(b)

Figure 2. Schematic of CBA concept design; a) CBA Design I; b) CBA Design II

\subsection{Conceptual design evaluation}

In this work, the evaluation was carried out using the integration of Design Failure Mode and Effect Analysis (DFMEA) and SOLIDWORKS Motion Analysis. The DFMEA method helps to recognize the potential failure effects, the potential causes of the failure, and the methods of prevention based on individual components and connections between each component. Then, the potential failure items for both CBA concept designs were obtained to analyse the potential failure based on the calculation of risk priority number (RPN) .

The information gathered from DFMEA was used in SOLIDWORKS Motion Analysis to identify stress performance analysis for each CBA conceptual design. The analysis used the assembly mates along with part contact and a robust physics-based solver to determine the physical movements of an assembly under the assigned load. Figure 3 shows the flowchart setup for this analysis. With the calculated assembly motion and forces, a structural analysis of the components can be performed. The analysis focused on the stress condition that occurred on the critical parts. Figure 4 shows the geometrical setup of the CBA concept design which include the boundary condition (BC) for each component. Fixed guide was set as a datum in this analysis. The constraints and the 
applied load were selected based on the working principle of the basic idea of the CBA. The contact between components was defined as Solid Body Contact to prevent components from penetrating each other during motion. This setup was applied to both CBA concept designs for its analysis.

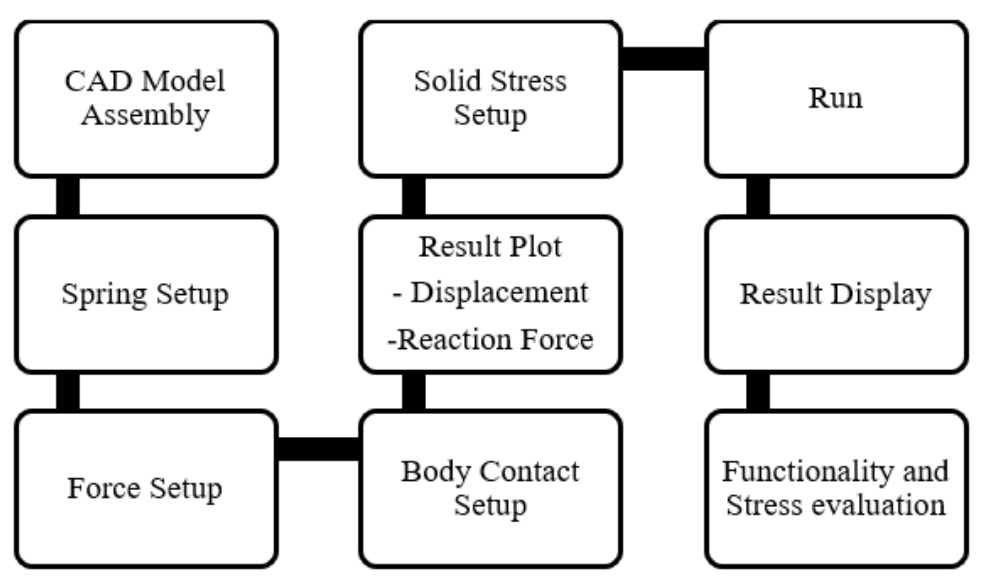

Figure 3. Motion Analysis Setup

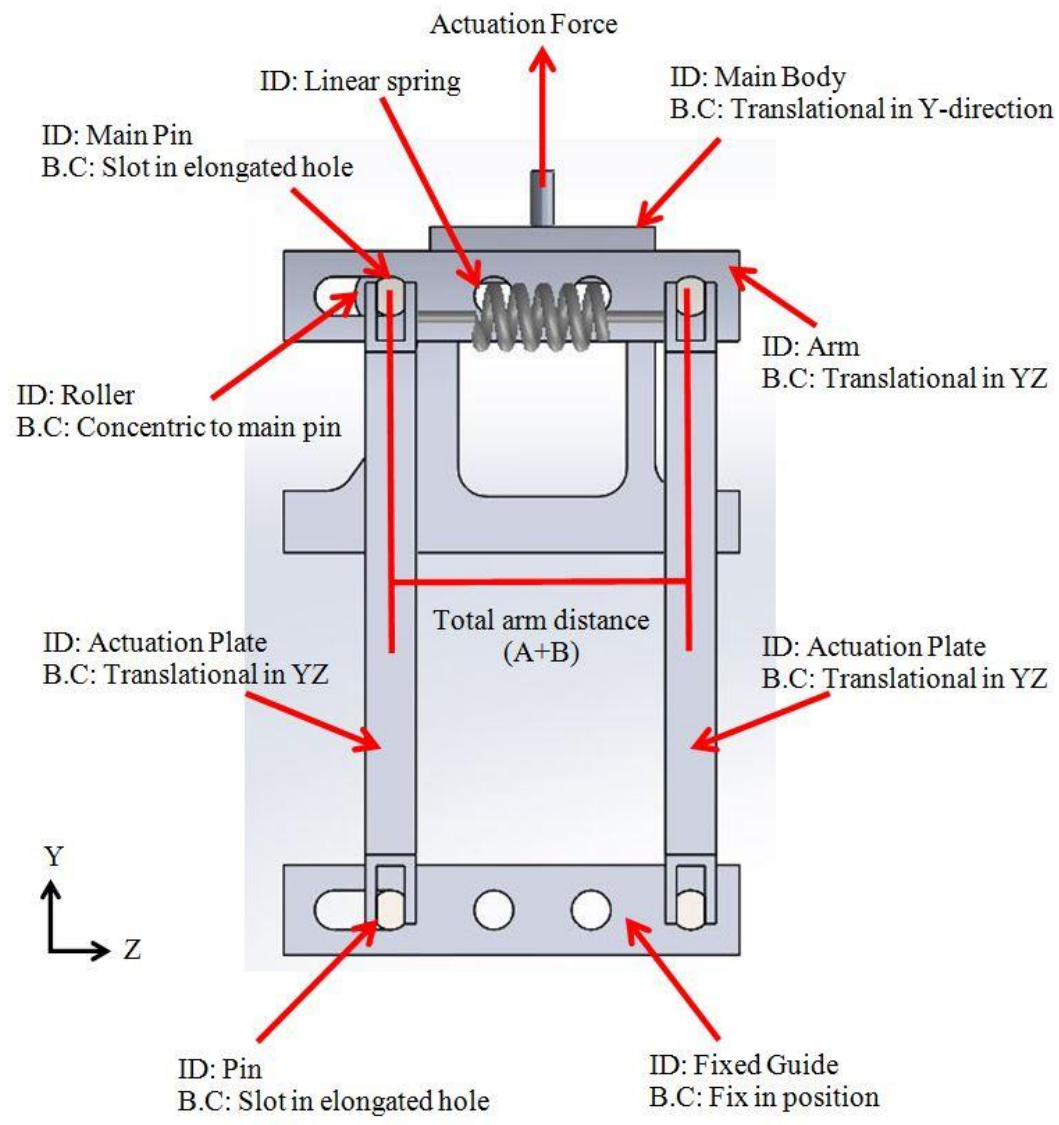

Figure 4. SOLIDWORKS Motion Setup

\subsection{RESULTS AND DISCUSSION}

\subsection{Design failure mode and effect analysis}

Based on the analysis of connection and relation for each component, the potential failure items for each CBA concept design are listed in Table 1. In this table, the first column lists the identification of the CBA concept design. Then, the potential failure item with its function on each CBA is listed in the second column. According to the second column, the main pin and the cam roller were determined as the critical items that had the potential to fail. The main pin on the CBA Design I was used to allow the actuation force on the front and rear brake to follow the expending contour of the main body. It is because the expanding contour on the main body plays a significant role in controlling the nonlinear force distribution to the front and rear brake. However, in CBA Design 
II, the cam roller was used to control the horizontal distance of the arm. The nonlinear force distribution to the front and the rear brake was obtained by controlling this horizontal distance. Once the function of the main pin and the cam roller was listed, the potential failure mode in relation to this function was identified. The potential failure mode was listed in the third column. Based on the third column, the potential failure mode of the main pin was determined as a fracture. The cam roller was potentially unable to rotate relatively to the main body movement. After that, the effects of each failure mode from the perspective of evaluated components were considered. This potential effect of failure mode was entered into the fourth column. In CBA concept design analysis, it shows that the failure of the main pin or the cam roller may cause the failure of the CBA to distribute forces to the front and the rear brake.

Once the potential effect for each failure mode was documented, the severity of this failure was evaluated. The severity ranking was determined based on the severity rating table [19]. It was recorded in the fifth column. Based on the severity rating table, the severity of all failures was ranked at eight. All the potential failure was ranked as very high severity because it contributed to the vehicle being inoperable with loss of primary function. The potential cause of the failure was expected due to the design specification and material specification of the main pin or the cam roller. Then, the occurrence ranking was determined based on the occurrence rating table [19]. The occurrence rating for both concept designs was ranked at two. This occurrence rating scale was entered into the seventh column. This value represented the probability of the failure that could have occurred during the CBA operation.

Instead of identifying the potential cause of failure, recommending design control and action for each CBA concept design needs to be addressed and entered into Table 1. From this CBA study, the potential failure can be detected based on design criteria and computational analysis. All information was entered into the eighth column. Then, the detection rating was assigned based on the detection rating as shown in Table 2 . The chances of the suggested approach to detect the failure were very high in CBA Design I. Based on the detection table, it was ranked into two and listed in the ninth column of the table. However, the chances of the suggested approach to detect the failure were high for CBA Design II, which was ranked at three.

Once the severity, occurrence, and detection rating were listed in the table, the RPN for each CBA concept design was computed based on Equation (1). The results of the RPN are shown in the tenth column of the table. According to the RPN value in this column, the CBA Design I had an RPN value of 32 (S, O, and D were 8, 2, and 2, respectively). Meanwhile, CBA Design II had an RPN value of 48 (S, O, and D were 8, 3, and 2, respectively). After the RPN was calculated, the recommended corrective actions were determined and entered into the DFMEA table. For the CBA concept design evaluation, further RPN analysis based on the recommended action was not carried out in the present study.

The CBA concept design is said to have less potential failure if the RPN is among the lowest. According to the RPN evaluation, the less potential failure of the CBA was found for CBA Design I. It is because the RPN value for this CBA concept design was 32 RPN scores, which was lower than CBA Design II that obtained 48 RPN scores. Therefore, the CBA Design I was determined as the best CBA concept design due to the lower RPN value compared to CBA Design II.

$$
R P N=O \times S \times D
$$

\subsection{Stress analysis}

Other than RPN analysis, the stress on the main pin was also analysed. It is because the main pin plays a major role in transmitting the force to the front and rear brake. This analysis aims to identify the CBA concept design that produces low stress during the actuation. Figure 5 shows the stress contour on the main pin for both concept designs in which the yield strength value for the material used is $2.206 \times 10^{8} \mathrm{~N} / \mathrm{m}^{2}$. This value represents the maximum limit of the stress that the main pin can withstand before the failure occurs. From this analysis, the maximum stress for both concept designs did not exceed the maximum limit of stress. However, by comparing both stress values, the highest stress was identified in CBA Design II, which was $1.387 \times 10^{8} \mathrm{~N} / \mathrm{m}^{2}$. Meanwhile, the stress that occurred in CBA Design I was lower than CBA Design II, which was $6.603 \times 10^{3} \mathrm{~N} / \mathrm{m}^{2}$. The linear slope design of the tilted position on CBA Design I was identified as the contributing factor to the lower stress result. Based on this design, the frictional force at the contacting surface between the roller and linear slope was smaller than CBA Design II. Thus, the roller will slide with minimum stress on the main pin. 
Table 1: Functional DFMEA for CBA conceptual design

\begin{tabular}{|c|c|c|c|c|c|c|c|c|c|c|}
\hline ID & Item / Function & $\begin{array}{c}\text { Potential } \\
\text { Failure } \\
\text { Mode } \\
\text { (Functional } \\
\text { Failure) }\end{array}$ & $\begin{array}{l}\text { Potential } \\
\text { Effect(s) } \\
\text { of Failure }\end{array}$ & 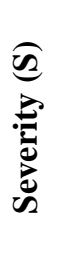 & $\begin{array}{c}\text { Potential } \\
\text { Cause(s) } \\
\text { / Mechanism(s) } \\
\text { of Failure }\end{array}$ & 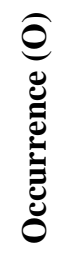 & $\begin{array}{c}\text { Current } \\
\text { Design } \\
\text { Controls } \\
\text { - Detection }\end{array}$ & 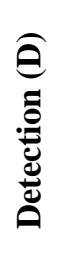 & $\underset{\underline{a}}{Z}$ & $\begin{array}{c}\text { Recommended } \\
\text { Actions }\end{array}$ \\
\hline CBA Design I & $\begin{array}{l}\text { Main Pin - Allowed } \\
\text { actuation to follow } \\
\text { the main body }\end{array}$ & Fracture & $\begin{array}{l}\text { fail to distribute } \\
\text { forces to the front } \\
\text { and rear brake }\end{array}$ & 8 & $\begin{array}{l}\text { design } \\
\text { specification, } \\
\text { material spec }\end{array}$ & 2 & $\begin{array}{l}\text { design criteria } \\
\& \text { CAE } \\
\text { analysis }\end{array}$ & 2 & 32 & $\begin{array}{c}\text { to follow design } \\
\text { criteria and run } \\
\text { durability test }\end{array}$ \\
\hline CBA Design II & $\begin{array}{c}\text { Roller Cam - } \\
\text { Allowed horizontal } \\
\text { displacement of the } \\
\text { arm }\end{array}$ & $\begin{array}{l}\text { Cannot } \\
\text { Rotate }\end{array}$ & $\begin{array}{l}\text { fail to distribute } \\
\text { forces to the front } \\
\text { and rear brake }\end{array}$ & 8 & $\begin{array}{l}\text { design } \\
\text { specification, } \\
\text { material spec }\end{array}$ & 2 & $\begin{array}{l}\text { design criteria } \\
\text { \& CAE } \\
\text { analysis }\end{array}$ & 3 & 48 & $\begin{array}{c}\text { to follow design } \\
\text { criteria and run } \\
\text { durability test }\end{array}$ \\
\hline
\end{tabular}

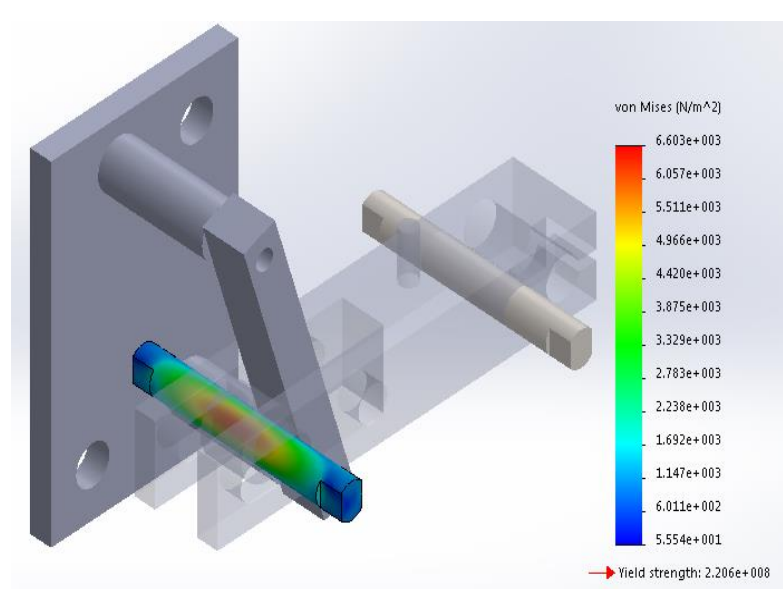

(a)

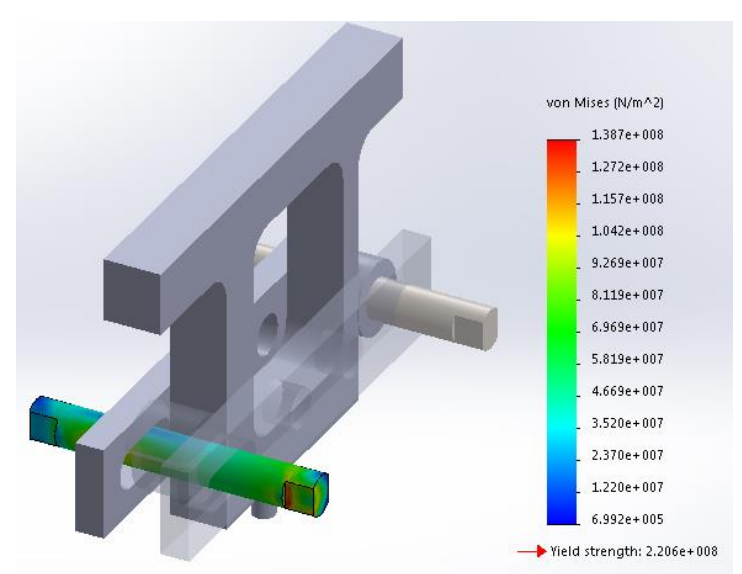

(b)

Figure 5. Stress contour analysis; a) CBA design I; and b) CBA design II 
Table 2: Detection rating for DFMEA [19]

\begin{tabular}{|c|c|c|}
\hline Detection & Description & Criteria \\
\hline 1 & Very high & $\begin{array}{l}\text { Discrepant parts cannot be made because the item has been error } \\
\text { proofed by process/product design }\end{array}$ \\
\hline 2 & Very high & $\begin{array}{l}\text { Error proofed or gauging inspection. Error detection in-station } \\
\text { (automatic gauging with automatic stop feature). Cannot pass } \\
\text { discrepant part }\end{array}$ \\
\hline 3 & High & $\begin{array}{l}\text { Error proofed or gauging inspection. Error detection in-station, OR in } \\
\text { subsequent operations by multiple layers of acceptance: supply, } \\
\text { select, install, verify. Cannot accept discrepant part }\end{array}$ \\
\hline 4 & Moderately high & $\begin{array}{l}\text { Error proofed or gauging inspection. Error detection in subsequent } \\
\text { operations, OR gauging performed on setup and first-piece check (for } \\
\text { setup causes only) }\end{array}$ \\
\hline 5 & Moderate & $\begin{array}{l}\text { Gauging inspection. Control is based on variable gauging after parts } \\
\text { have left the station, OR Go/No Go gauging performed on } 100 \text { percent } \\
\text { of the parts after parts have left the station }\end{array}$ \\
\hline 6 & Low & $\begin{array}{l}\text { Gauging or manual Inspection. Control is achieved with charting } \\
\text { methods, such as statistical process control (SPC) }\end{array}$ \\
\hline 7 & Very low & $\begin{array}{l}\text { Manual inspection. Control is achieved with double visual inspection } \\
\text { only }\end{array}$ \\
\hline 8 & Remote & Manual inspection. Control is achieved with visual inspection only \\
\hline 9 & Very remote & $\begin{array}{l}\text { Manual inspection. Control is achieved with indirect or random } \\
\text { checks only }\end{array}$ \\
\hline 10 & Almost impossible & Manual inspection. Cannot detect or is not checked \\
\hline
\end{tabular}

\subsection{Concept Selection}

In this section, further investigation of each CBA concept evaluation was carried out. All the information gathered from DFMEA and SOLIDWORK Motion Analysis was analysed. This analysis aims to select the best CBA concept design for further CBA development. The summary of concept evaluations that were carried out using DFMEA and SOLIDWORKS Motion Analysis is shown in Table 3. Based on this table, the lowest stress on the main pin was obtained by CBA Design I. In terms of RPN value, CBA Design I scored a lower RPN compared to CBA Design II. The RPN value for CBA Design I was 32 RPN score. The 48 RPN score was obtained by CBA Design II. All this information was taken into consideration to select the CBA concept design.

Table 3: Summary of concepts evaluation

\begin{tabular}{ccc}
\hline ID & Stress N/m & RPN \\
\hline CBA Design I & $6.603 \times 10^{3}$ & 32 \\
CBA Design II & $1.387 \times 10^{8}$ & 48 \\
\hline
\end{tabular}

The concept selection is based on qualitative evaluation [20]. The best CBA concept design is proposed at this stage. Table 4 shows the CBA concept design selection matrix. Based on this table, the evaluated factors were listed in the first row. The CBA concept design was evaluated based on stress and RPN value. The information given in the second row was about the relative importance of criteria for the successful CBA concept design. The importance of these criteria, also known as criteria weight, was rated on a scale of 1-10, where 10 showed the most important criterion. Based on the CBA concept design analysis, stress was identified as the main selection criteria for the CBA concept design. Thus, it rated with 10 and followed by the criteria of RPN with a scale of 8 . In the third row, the characteristics of the CBA concept design that exhibited particular criteria were scored. The scale of 0-4 was used as the grade score. The grade was based on the evaluation ranking for each particular factor with the best grade of 4 for the scale. Then, the total score for a particular concept was given in the final column. The total score is the sum product of multiplication between the grade score with a rated scale for each particular criterion. Based on this total score, the CBA concept design that obtained the total highest score was chosen.

In this analysis, the total score obtained by the CBA Design I was 72, while CBA Design II just scored 34. Therefore, CBA Design I was selected as the CBA concept design since it obtained a higher score compared to CBA Design II. 
Table 4: Concept selection matrix

\begin{tabular}{cccc}
\hline $\begin{array}{c}\text { Concept Selection } \\
\text { Matrix }\end{array}$ & Weight & $\begin{array}{c}\text { CBA } \\
\text { Design I }\end{array}$ & $\begin{array}{c}\text { CBA } \\
\text { Design II }\end{array}$ \\
\hline Stress & 10 & 4 & 1 \\
RPN & 8 & 4 & 3 \\
Total Score & & 72 & 34 \\
\hline
\end{tabular}

\subsection{CONCLUSION}

As a conclusion, two mechanism designs of the CBA were proposed in this study. Both concepts were evaluated based on DFMEA and SOLIDWORKS Motion Analysis. Based on this study, CBA Design I was selected as the CBA concept design. The selection was made based on the highest score gained by this concept design compared to CBA Design II in qualitative evaluation. The fixed main body design with a tilted position linear slope in CBA Design I has the potential to actuate and distribute the ideal nonlinear brake force to the front and rear brake with less potential of failure. Therefore, the proposed mechanism design will be used as a base mechanism design for further CBA development.

\section{ACKNOWLEDGEMENT}

The authors acknowledge the technical support from Universiti Teknologi MARA and the scholarship by the Ministry of Higher Education under the IPTA Academic Training Scheme awarded to the first author. The financial support provided by the Malaysia Ministry of Science, Technology, and Innovation (MOSTI) through the Grant Scheme (Science Fund) (06-01-01-SF0809) is also acknowledged.

\section{REFERENCES}

[1] World Health Organization, "Global Status Report on Road,” 2018.

[2] S. Wannapor, S. Koetniyom, and J. Carmai, "Development and evaluation of advanced seat and helmet for safer motorcycle users," IOP Conf. Ser. Mater. Sci. Eng., vol. 501, no. 1, 2019, doi: 10.1088/1757899X/501/1/012015.

[3] M. M. Abdul Manan, A. Várhelyi, A. K. Çelik, and H. H. Hashim, "Road characteristics and environment factors associated with motorcycle fatal crashes in Malaysia," IATSS Res., vol. 42, no. 4, pp. 207-220, 2018, doi: 10.1016/j.iatssr.2017.11.001.

[4] L. T. Truong, H. T. T. Nguyen, and C. De Gruyter, "Mobile phone use while riding a motorcycle and crashes among university students," Traffic Inj. Prev., vol. 20, no. 2, pp. 204-210, 2019, doi: 10.1080/15389588.2018.1546048.

[5] K. Ambak, R. Atiq, and R. Ismail, "Intelligent Transports System for motorcycle safety and issues," Eur. J. Sci. Res., vol. 28, no. 4, pp. 600-611, 2009, Accessed: Oct. 04, 2012. [Online]. Available: http://helibikes.co.uk/Resources/MC Intelligent Transport System.pdf.

[6] A. Jimenez, J. Pablo, R. Zarama, and J. Yerpez, "A case study analysis to examine motorcycle crashes in Bogota , Colombia," J. Safety Res., vol. 52, pp. 29-38, 2015, doi: 10.1016/j.jsr.2014.12.005.

[7] O. Cherta Ballester et al., "Analysis of trunk impact conditions in motorcycle road accidents based on epidemiological, accidentological data and multibody simulations," Accid. Anal. Prev., vol. 127, no. January, pp. 223-230, 2019, doi: 10.1016/j.aap.2019.03.006.

[8] D. Atalar and P. Thomas, "Powered two-wheeler crash scenario development," Accid. Anal. Prev., vol. 125, no. January, pp. 198-206, 2019, doi: 10.1016/j.aap.2019.02.001.

[9] C. Ding, M. Rizzi, J. Strandroth, U. Sander, and N. Lubbe, "Motorcyclist injury risk as a function of real-life crash speed and other contributing factors," Accid. Anal. Prev., vol. 123, pp. 374-386, 2019, doi: 10.1016/j.aap.2018.12.010.

[10] E. R. Teoh and M. Campbell, "Role of motorcycle type in fatal motorcycle crashes.," J. Safety Res., vol. 41, no. 6, pp. 507-12, Dec. 2010, doi: 10.1016/j.jsr.2010.10.005.

[11] R. Isermann, R. Mannale, and K. Schmitt, "Collision-avoidance systems PRORETA: Situation analysis and intervention control,” Control Eng. Pract., vol. 20, no. 11, pp. 1236-1246, Jul. 2012, doi: https://doi.org/10.1016/j.conengprac.2012.06.003.

[12] P. Seiniger, K. Schröter, and J. Gail, "Perspectives for motorcycle stability control systems," Accid. Anal. Prev., vol. 44, no. 1, pp. 74-81, 2012, doi: 10.1016/j.aap.2010.11.018.

[13] Y. T. Lin, C. Y. Tseng, J. H. Kuang, and Y. M. Hwang, "A design method for a variable combined brake system for motorcycles applying the adaptive control method," Machines, vol. 9, no. 2, pp. 1-18, 2021, doi: 10.3390/machines9020031.

[14] K. Bayar, R. Biasini, S. Onori, and G. Rizzoni, "Modelling and control of a brake system for an extended range electric vehicle equipped with axle motors," Int. J. Veh. Des., vol. 58, no. 2-4, pp. 399426, 2012, doi: 10.1504/IJVD.2012.047387.

[15] L. Sun et al., "Influence of methane on hot filament CVD diamond films deposited on high-speed steel 
substrates with WC-Co interlayer," Huagong Xuebao/CIESC J., vol. 60, no. 2, pp. 444-449, 2009, doi: $10.1007 / \mathrm{s} 11771$.

[16] V. Arakelian and S. Briot, "Simultaneous inertia force/moment balancing and torque compensation of slider-crank mechanisms," Mech. Res. Commun., vol. 37, no. 2, pp. 265-269, 2010, doi: 10.1016/j.mechrescom.2009.11.007.

[17] P. Kitrungloadjanaporn, A. Phothong, and M. Precharattana, "Seesaw Balancing: A Hands-On Model to Understand Moment of Force in Classroom," Appl. Mech. Mater., vol. 879, no. March, pp. 269-275, 2018, doi: 10.4028/www.scientific.net/amm.879.269.

[18] R. S. Berkof, "Complete force and moment balancing of inline four-bar linkages," Mech. Mach. Theory, vol. 8, no. 3, pp. 397-410, Sep. 1973, doi: 10.1016/0094-114X(73)90076-1.

[19] S. Vinodh and D. Santhosh, "Application of FMEA to an automotive leaf spring manufacturing organization," TQM J., vol. 24, no. 3, pp. 260-274, 2012, doi: 10.1108/17542731211226772.

[20] G. S. Mali, "Novel Escapement Mechanism using a Compliant Mechanism and a Piezoelectric Actuator," 2007. 